\title{
BMJ Open Cash transfer scheme for people with tuberculosis treated by the National TB Programme in Western India: a mixed methods study
}

Bharatkumar Hargovandas Patel (D) , ${ }^{1}$ Kathiresan Jeyashree, ${ }^{2}$ Palanivel Chinnakali, ${ }^{3}$ Mathavaswami Vijayageetha, ${ }^{4}$ Kedar Gautambhai Mehta, ${ }^{1}$ Bhavesh Modi, ${ }^{5}$ Paragkumar Dhirajlal Chavda, ${ }^{1}$ Paresh V Dave, ${ }^{6}$ Chintu Chhitabhai Zala, ${ }^{7}$ Hemant Deepak Shewade, ${ }^{8,9}$ Dipak M Solanki, ${ }^{10}$ Ajay M V Kumar ${ }^{8,9,11}$

To cite: Patel BH, Jeyashree K, Chinnakali P, et al. Cash transfer scheme for people with tuberculosis treated by the National TB Programme in Western India: a mixed methods study. BMJ Open 2019:9:e033158. doi:10.1136/ bmjopen-2019-033158

- Prepublication history and additional material for this paper are available online. To view these files, please visit the journal online (http://dx.doi. org/10.1136/bmjopen-2019033158).

Received 23 July 2019

Revised 26 November 2019

Accepted 27 November 2019

Check for updates

(c) Author(s) (or their employer(s)) 2019. Re-use permitted under CC BY-NC. No commercial re-use. See rights and permissions. Published by BMJ.

For numbered affiliations see end of article.

\section{Correspondence to}

Dr Bharatkumar Hargovandas

Patel;

drbharatpatel1@gmail.com

\section{ABSTRACT}

Objectives This study aimed to assess the coverage and explore enablers and challenges in implementation of direct benefit transfer (DBT) cash incentive scheme for patients with tuberculosis (TB).

Design This is a mixed methods study comprising a quantitative cohort and descriptive qualitative study. Setting The study was conducted in City TB Centre, Vadodara, Western India.

Participants We used routinely collected data under the National TB Programme (NTP) on patients with TB notified between April and September 2018 and initiated on first-line anti-tuberculosis treatment (ATT) to assess the coverage of DBT. We interviewed NTP staff and patients to understand their perceptions.

Primary and secondary outcome measures The study outcomes are receipt of DBT (primary), time to receipt of first instalment of DBT and treatment outcome.

Results Among 1826 patients, 771 (42.2\%) had received at least one instalment. Significantly more patients from the public sector had received DBT (at least one instalment) compared with those from private sector (adjusted relative risk $(\operatorname{adjRR})=16.3 ; 95 \% \mathrm{Cl} 11.6$ to 23.0). Among public sector patients, $7.3 \%$ (49/671) had received first instalment within 2 months of treatment initiation. Median (IQR) time to receipt of first instalment was $5.2(3.4,7.4)$ months. Treatment in private sector, residing outside city limits and being HIV non-reactive were significantly $(p<0.001)$ associated with longer time to receipt. Timely and sufficient fund release, adequate manpower and adequate logistics in TB centre were the enablers. Inability of patients to open bank accounts due to lack of identity/residence proof, their reluctance to share personal information and inadequate support from private providers were the challenges identified in implementation.

Conclusion During the early phase of DBT implementation, the coverage was low and there were delays in benefit transfer. Facilitating opening of bank accounts for patients by NTP staff and better support from private providers may improve DBT coverage. Repeat assessment of DBT coverage after streamlining of implementation is recommended.

\section{Strengths and limitations of this study}

- The study is first of its kind in India, and done early in the implementation of direct benefit transfer (DBT) scheme under pragmatic conditions to provide timely and realistic inputs to the programme to improve effectiveness.

- The study benefits from mixed methods design, where the quantitative and qualitative components validated and complemented each other.

- Considering the teething problems in early phase of implementation, coverage of DBT may have been lower in this study for the first 6-month cohort of beneficiaries of DBT scheme.

- The study findings were limited by the exclusion of patients with multidrug-resistant TB and lack of data on socioeconomic status.

\section{BACKGROUND}

Patients with tuberculosis (TB) suffer high outof-pocket costs for diagnosis and treatment, despite the availability of free TB care in most settings. The average expenditure incurred by patients in low-income and middle-income countries towards diagnosis and treatment of TB ranges from $\$ 55$ to $\$ 8198,{ }^{1}$ placing their households at higher risk of catastrophic costs due to TB care. ${ }^{2-6}$ Catastrophic costs create access and adherence barriers, which, in turn, are associated with adverse TB treatment outcomes including death, failure of treatment, loss to follow-up, recurrence and multidrug-resistant (MDR) TB. ${ }^{7}$

The WHO launched the 'End TB Strategy' in line with United Nations health-related Sustainable Development Goal 3. ${ }^{89}$ Besides reduction of TB incidence rate and mortality, the strategy aims to 'achieve zero catastrophic cost for affected families due to TB' by $2020 .^{9}$ 
Worldwide, poverty reduction strategies are increasingly being woven into TB control programmes. Various social protection initiatives such as cash transfers, food baskets and social insurance are endorsed to help prevent catastrophic costs. Cash transfer initiatives can follow one of the three approaches: TB sensitive (broadly to include patients with risk factors or susceptibility to TB), TB specific (exclusively for patients with $\mathrm{TB}$ ) or TB inclusive approach (including $\mathrm{TB}$ as one of the conditions among others). ${ }^{10}$

Cash transfers have been previously implemented and found successful in the fields of HIV and malnutrition in improving health outcomes. ${ }^{11}$ In the context of TB, cash transfers for patients with TB have been found to be more effective than non-cash support strategies in improving clinic attendance, increasing patient awareness of timing of their follow-up visits, retention in the programme and completion of treatment. ${ }^{1213}$

As per the directive of 'National strategic plan (NSP) for tuberculosis elimination 2017-2025', the Government of India launched the 'Nikshay Poshan Yojana' nationwide, a direct benefit transfer (DBT) scheme, from 1 April 2018. ${ }^{14}$ Under this scheme, all notified patients with TB nikshay portal (an electronic, case-based, web-based notification and information management system) receive Indian rupees (INR) 500 per month ( US\$7) throughout the course of treatment for TB. The cash transfer is primarily for nutrition support (as there is a coexistence of food insecurity and undernutrition with a large burden of TB in India). Other purposes are to increase treatment adherence and to provide financial assistance for eliminating catastrophic expenditure. The scheme adopted a DBT mechanism for the transfer of monetary support to ensure that the funds reach rightful recipients in a timely manner. Having a bank account is mandatory for receiving cash benefit. Since there are multiple steps involved in verification and transfer of money to the bank account of patients, there might be challenges in implementation. It is vital to assess the coverage of this scheme and to explore the challenges from both patient and provider's perspectives to inform policy for effective implementation of the scheme. A combination of quantitative and qualitative assessment methods will help us to understand the above comprehensively. Therefore, we aimed to determine the coverage of DBT and explore the enablers and challenges in its implementation in the city of Vadodara, Gujarat, India.

\section{METHODS}

\section{Study design}

This is a mixed methods study with a concurrent triangulation design ${ }^{15}$; a cohort study involving routine data collected in the National TB Programme (NTP) and a descriptive qualitative component. Concurrent triangulation design is a type of mixed methods study in which qualitative and quantitative data are collected concurrently, analysed separately and then compared and/or combined. We used this method to combine the findings of quantitative and qualitative part of the study, and thereby to have a holistic picture on the implementation of DBT scheme.

\section{Setting}

\section{General setting}

The study was conducted in Vadodara (formerly known as Baroda) city, the third largest city in the state of Gujarat, West India, with a population of about 1.8 million. ${ }^{16}$ The city has four administrative zones, namely, north, south, west and east.

\section{Specific setting}

Gujarat had an annual total TB notification rate of 224/100000 per year with 149061 patients with TB registered with the NTP in 2017, of which 5368 were from Vadodara city. ${ }^{17}$ Among these 5368 patients, 3732 were notified from the public sector and 1636 fromthe private sector at a rate of 85 and 193 per 100000 per year. ${ }^{17}$ Under the NTP, each district, with an average population of around 1-2 million, has a district TB centre (DTC), which monitors the programme implementation for the entire district. In addition to DTCs, there are three city TB centres in Gujarat, one of which is in Vadodara city run by Vadodara Municipal Corporation and headed by a city TB officer. City TB Centre at Vadodara oversees eight tuberculosis units (subdistrict level) and 21 designated microscopy centres. All over India, details of all patients with TB are recorded in a web-enabled and case-based monitoring application called nikshay and similarly so in Vadodara city.

\section{DBT scheme (Nikshay Poshan Yojana)}

DBT scheme for patients with TB in India is officially known as Nikshay Poshan Yojana. Under this scheme, first instalment of INR 1000 for the first 2 months is expected to be disbursed immediately after starting treatment. The subsequent instalments (@ INR 1000 for every 2 months) are disbursed only if the patient has completed 2 months of treatment. Cash incentives are for the patient only and the amount is fixed, irrespective of household size or poverty level. Cash incentives are transferred to the bank account of patient (diagnosed at public or private sector) after the approval process from field to the public financial management system (PFMS) (figure 1). The benefits for paediatric patients with TB who do not hold bank accounts are deposited in the bank accounts of parents/ guardians. PFMS is a web-based financial management platform, set-up and maintained by the Government of India to disburse cash benefits and subsidies electronically to the citizens of India. It aims to transfer the benefits in a timely manner and is intended to bring in efficiency, transparency and accountability in the government system.

\section{Study population}

Quantitative

All patients with TB notified on nikshay portal of City TB Centre, Vadodara between 1 April 2018 and 30 September 2018 and initiated on first-line anti-TB treatment were included in the study. This includes patients notified 


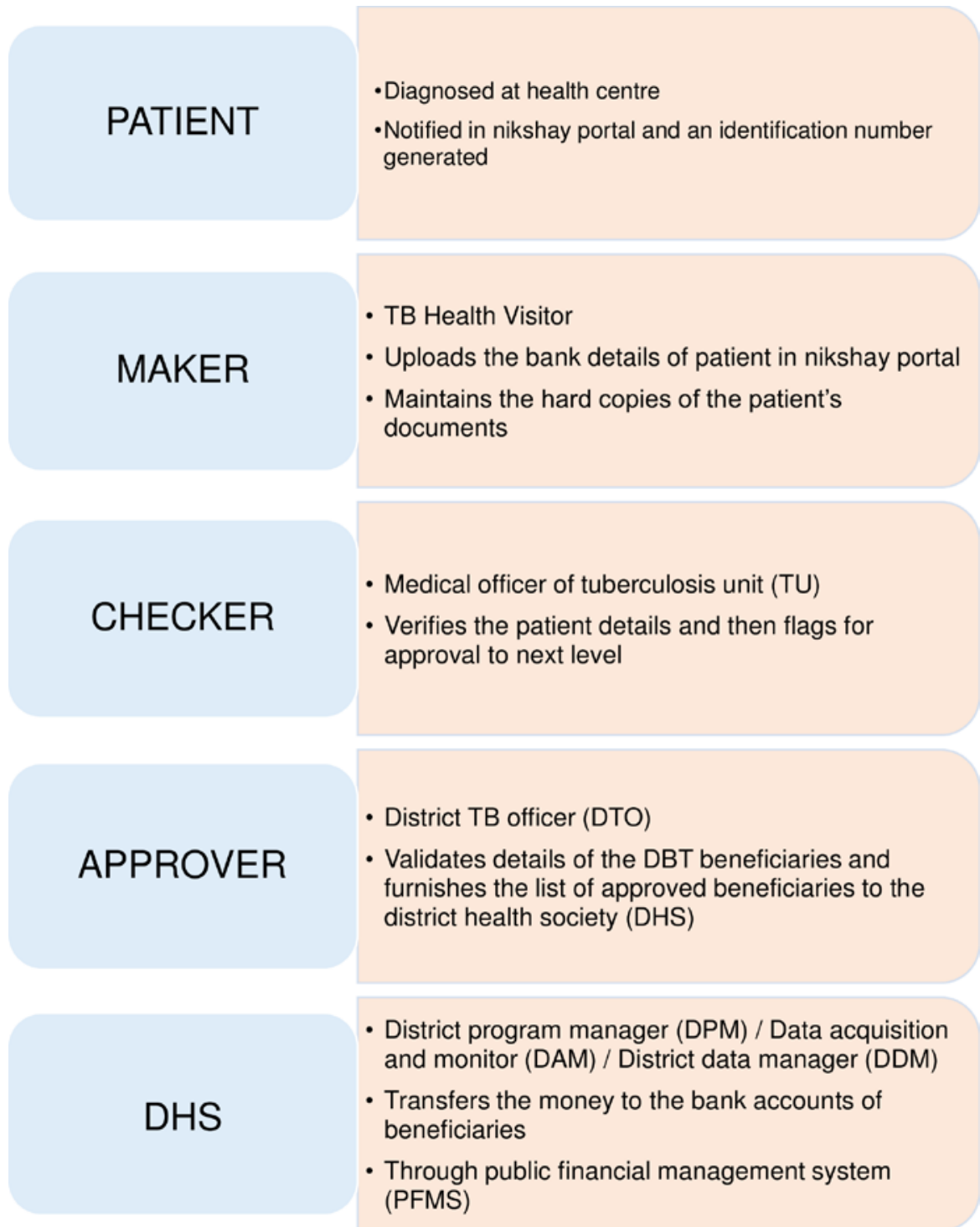

Figure 1 Process of approval and transfer of cash incentive to patients with tuberculosis under the direct benefit transfer (DBT) scheme in India, 2018.

from the private health sector as well. Standard treatment duration for 'New' patients' was 6 months and for 'Previously treated' patients' was 8 months. Patients with known drug-resistant TB were excluded from the study because they require longer follow-up to ascertain their DBT receipt status, which was not feasible within study period. The patients who were notified on nikshay portal of City TB Centre, Vadodara but initiated on treatment at other district/city TB centres or transferred out after treatment initiation were also excluded from the study because their DBT details were no longer available with transferring facility (City TB Centre, Vadodara) at the time of censoring date (31 May 2019) for data collection.

\section{Qualitative}

Purposive sampling was used to recruit participants for the qualitative part of the study. Healthcare providers (programme staff including treating physicians) engaged in the implementation of DBT scheme were the key informants to explore facilitators and challenges for DBT implementation and possible solutions for it. Eight key informant interviews were conducted to cover all levels of healthcare providers (seven male, 1 female, age range 32-56 years). Eleven in-depth interviews were conducted with patients (parent or guardian in case of paediatric patient) to understand their perceived utility, pattern of utilisation and experiences in availing DBT (seven male, four female, age range 26-70 years). New and retreatment patients, recipients and non-recipients of the DBT were purposively selected for maximum variation in the sample.

\section{Data collection}

Quantitative

Quantitative data were extracted from nikshay portal of City TB Centre, Vadodara and PFMS portal with a censoring date of 31 May 2019 (online supplementary files 1 and 2). Entry of records to the nikshay and PFMS was done by trained health functionaries of the National 
TB Programme, which was reviewed by supervisory cadre to ensure high quality of entered data.

\section{Qualitative}

The principal investigator (PI) conducted key informant and patient interviews with the help of structured field-tested interview guide (online supplementary file 3). Interviews were conducted in Gujarati, English or Hindi, depending on the preference of the participant. PI is a native of the state, fluent in English, Gujarati and Hindi. PI has a good in-depth understanding of the social context and of ТВ control in India. He is a faculty in medical college with a specialisation in community medicine and trained in qualitative research methods. There was no relation between PI and respondents. Interviews were conducted after obtaining written informed consent from the participant and at a date, time and place convenient to participants. Interviews were audio recorded (with consent). Besides participant and researcher, no other person was present at the time of interview. Average duration of interview was less than $15 \mathrm{~min}$ for key informants and less than $10 \mathrm{~min}$ for patients. There were no dropouts for key informant interviews. Two patients selected could not be interviewed because they were out of station for long period. There were no repeat interviews. After the interview was over, the summary of the interviews was read back to the participants to ensure participant validation.

\section{Analysis and statistics}

Quantitative

Data were analysed using EpiData analysis software V.2.2.2.178 (EpiData Association, Odense, Denmark) and Stata V.13.0 (StataCorp, Texas, USA). The censoring date for assessment of receipt of payment was 31 May 2019. Time to receipt of first instalment was compared among various subgroups using Mann-Whitney $\mathrm{U}$ test (two categories) and Kruskal-Wallis $\mathrm{H}$ test (more than two categories). Factors associated with receipt/non-receipt of the
DBT were examined using $\chi^{2}$ test. A p value of $\leq 0.05$ was considered statistically significant. Factors $<0.2$ in univariate analysis were entered into multivariable analysis using $\log$ binomial regression.

\section{Key study outcomes}

1. Recipient of DBT: patient with TB (enrolled in this study) who received minimum of one instalment of DBT irrespective of time of disbursement. The reason is that, in the process of receipt of DBT instalments, receipt of first instalment is crucial.

2. Non-recipient of DBT: patient with TB (enrolled in this study) who did not received any instalment of DBT irrespective of time of disbursement.

3. Time to receipt first DBT instalment: time interval between date of treatment initiation and date of disbursal of first instalment of cash transfer to the bank account of beneficiary as per the PFMS record.

4. Successful treatment outcome: treatment outcome reported in nikshay portal by NTP staff as 'cured' or 'treatment completed' (table 1).

5. Unsuccessful treatment outcome: treatment outcome reported in nikshay portal by NTP staff as 'treatment failure', 'loss to follow-up', 'died' or 'treatment regimen changed' (table 1).

\section{Qualitative}

Interviews were audio recorded and transcribed verbatim. Transcripts were prepared on the same day by BHP (PI). Data were processed using manual descriptive content analysis. Coding was done by two investigators (BHP and PDC) independently which was then reviewed by the third investigator $(\mathrm{KM})$. The decision on coding rules and theme generation was done by using standard procedures as described by Attride-Sterling. ${ }^{18}$ This process involves grouping basic themes into organising themes and then into a global theme. Any discrepancies between

Table 1 Operational definitions of TB treatment outcomes under National Tuberculosis Programme, India

\section{Treatment outcome Definition}

Cured Microbiologically confirmed TB patients at the beginning of treatment who was smear or culture negative at the end of the complete treatment.

Treatment completed A TB patient who completed treatment without evidence of failure or clinical deterioration, but with no record to show that the smear or culture results of biological specimen in the last month of treatment was negative, either because test was not done or because result is unavailable.

\begin{tabular}{ll} 
Failure & A TB patient whose biological specimen is positive by smear or culture at end of treatment. \\
Lost to follow-up & A TB patient for whom treatment was interrupted for one consecutive month or more. \\
$\begin{array}{l}\text { Not evaluated } \\
\text { Died }\end{array}$ & A TB patient for whom no treatment outcome is assigned. This includes 'transfer-out'. \\
Failure to respond & $\begin{array}{l}\text { A patient who has died during the course of anti-TB treatment. } \\
\text { respond clinically/ or deteriorates after 12 weeks of complaint intensive phase shall be deemed to have } \\
\text { failed response provided alternative diagnoses/reasons for non-response have been ruled out. }\end{array}$ \\
\hline
\end{tabular}

Source: Technical and Operational Guidelines for Tuberculosis Control in India. 2016. Central TB Division; Ministry of Health and Family Welfare; Government of India.

TB, tuberculosis. 
the two investigators (BHP and PDC) were resolved through discussion with a third coinvestigator (KM). Both inductive and deductive themes were generated. The findings are reported by using 'Consolidated Criteria for Reporting Qualitative Research'. ${ }^{19}$

\section{Patient and public involvement}

We did not involve patient and public in the design, conduct and/or reporting of this study.
RESULTS

Sociodemographic and clinical characteristics

Of 1826 enrolled patients, $958(52.5 \%)$ were from the public sector. Mean (SD) age of the participants was 38.4 (17.6) years and 1136 (62.2\%) were male. Bank accounts were available for 985 (53.9\%) patients. Among the 1169 patients with known HIV status, 24 (2.1\%) were reactive. New patients accounted for $86 \%$ of the study population and $1392(76 \%)$ had pulmonary TB (table 2). Of 945

Table 2 Demographic and clinical characteristics of patients with TB notified and initiated on first-line anti-TB treatment at City TB Centre, Vadodara, India, between April and September 2018 classified by direct benefit transfer (DBT) receipt status $(n=1826)$

\begin{tabular}{|c|c|c|c|c|c|c|c|c|c|}
\hline \multirow[b]{2}{*}{ Variable } & \multirow[b]{2}{*}{ Category } & \multicolumn{2}{|c|}{ Total* $^{*}$} & \multicolumn{3}{|c|}{ Non-recipients of DBT† } & \multirow[b]{2}{*}{$P$ value $\neq$} & \multirow[b]{2}{*}{$\begin{array}{l}\text { adjRR } \\
(95 \% \mathrm{Cl})\end{array}$} & \multirow[b]{2}{*}{$P$ value } \\
\hline & & $\mathbf{N}$ & $\%$ & $\mathbf{N}$ & $\%$ & $\begin{array}{l}\text { RR } \\
(95 \% \mathrm{Cl})\end{array}$ & & & \\
\hline Overall & & 1826 & 100 & 1055 & 57.8 & & & & \\
\hline \multicolumn{10}{|c|}{ Age (in years) } \\
\hline & Below 15 & 81 & 4.4 & 53 & 65.4 & 1.48 (0.92 to 2.36$)$ & 0.104 & 0.86 (0.47 to 1.58$)$ & 0.626 \\
\hline & $15-59$ & 1465 & 80.2 & 823 & 56.2 & 1 & & 1 & \\
\hline & 60 and above & 280 & 15.3 & 179 & 63.9 & 1.38 (1.06 to 1.80$)$ & 0.017 & 0.76 (0.54 to 1.07$)$ & 0.117 \\
\hline \multicolumn{10}{|l|}{ Gender } \\
\hline & Male & 1136 & 62.2 & 632 & 55.6 & 1 & & 1 & \\
\hline & Female & 690 & 37.6 & 423 & 61.3 & 1.26 (1.04 to 1.53$)$ & 0.017 & 1.05 (0.82 to 1.34$)$ & 0.697 \\
\hline \multicolumn{10}{|c|}{ Residence } \\
\hline & Within city§ & 1479 & 81.0 & 745 & 50.4 & 1 & & 1 & \\
\hline & Outside city§ & 318 & 17.4 & 282 & 88.7 & 7.72 (5.38 to 11.08$)$ & $<0.0019$ & 1.52 (0.99 to 2.34$)$ & 0.055 \\
\hline & Not reported & 29 & 1.6 & 28 & 96.6 & - & - & - & - \\
\hline \multicolumn{10}{|c|}{ Tuberculosis site } \\
\hline & Pulmonary & 1392 & 76.2 & 808 & 58.0 & 1 & & - & - \\
\hline & $\begin{array}{l}\text { Extra } \\
\text { pulmonary }\end{array}$ & 420 & 23.0 & 233 & 55.5 & 0.90 (0.72 to 1.12$)$ & 0.3519 & - & - \\
\hline & Not reported & 14 & 0.8 & 14 & 100.0 & - & - & - & - \\
\hline \multicolumn{10}{|c|}{ Patient type } \\
\hline & New & 1570 & 86.0 & 958 & 61.0 & 1 & & 1 & \\
\hline & $\begin{array}{l}\text { Previously } \\
\text { treated }\end{array}$ & 256 & 14.0 & 97 & 37.9 & $0.39(0.30$ to 0.51$)$ & $<0.001$ & 1.06 (0.77 to 1.45$)$ & 0.728 \\
\hline \multicolumn{10}{|c|}{ HIV status } \\
\hline & Reactive & 24 & 1.3 & 13 & 54.2 & 1.50 (0.67 to 3.38$)$ & 0.325 & 2.65 (1.16 to 6.08$)$ & 0.021 \\
\hline & Non-reactive & 1145 & 62.7 & 504 & 44.0 & 1 & & 1 & \\
\hline & Unknown & 657 & 36.0 & 538 & 81.9 & 5.75 (4.57 to 7.24$)$ & $<0.001$ & 1.16 (0.84 to 1.62$)$ & 0.374 \\
\hline \multicolumn{10}{|c|}{ Treatment sector } \\
\hline & Public & 958 & 52.5 & 283 & 29.5 & 1 & & & \\
\hline & Private & 868 & 47.5 & 772 & 88.9 & 19.2 (14.9 to 24.7 ) & $<0.001$ & 16.3 (11.6 to 23.0 ) & $<0.001$ \\
\hline
\end{tabular}

${ }^{*}$ Column percentages are shown for values in this column.

†Non-recipients of DBT-not received any instalment; irrespective of time of disbursement. Row percentages are shown for values in this column.

$\mp \chi^{2}$ test used.

$\S$ Administrative area of City TB Centre, Vadodara.

ICCalculated only among reported.

adjRR, adjusted relative risk; $R R$, relative risk. 
Table 3 Number of instalments received, total amount received and time to receipt first direct benefit transfer (DBT) instalment among patients with TB notified and initiated on first-line anti-TB treatment in the public sector at City TB Centre Vadodara, India, between April and September $2018\left(n=675^{\star}\right)$

\begin{tabular}{|c|c|c|c|c|c|c|c|}
\hline \multirow[b]{3}{*}{ Variable } & \multirow[b]{3}{*}{ Category } & \multicolumn{6}{|c|}{ Type of patient† } \\
\hline & & \multicolumn{2}{|l|}{ New } & \multicolumn{2}{|c|}{ Previously treated } & \multicolumn{2}{|c|}{ Overall } \\
\hline & & $\mathbf{n}$ & $\%$ & $\mathbf{n}$ & $\%$ & $\mathbf{n}$ & $\%$ \\
\hline \multirow{5}{*}{ No. of instalments received } & 1 & 26 & 5.0 & 5 & 3.3 & 31 & 4.6 \\
\hline & 2 & 29 & 5.5 & 15 & 10.0 & 44 & 6.5 \\
\hline & 4 & 52 & 9.9 & 67 & 44.9 & 119 & 17.7 \\
\hline & 5 & 18 & 3.4 & 12 & 8.1 & 30 & 4.5 \\
\hline & $>5$ & 25 & 4.9 & 7 & 4.7 & 32 & 4.5 \\
\hline \multirow[t]{2}{*}{ Total amount received (INR) } & Total & 526 & & 149 & & 675 & \\
\hline & Median & 3000 & & 3500 & & 3000 & \\
\hline \multirow{3}{*}{$\begin{array}{l}\text { Duration between treatment } \\
\text { initiation and receipt of first } \\
\text { instalment }\end{array}$} & 2-4 months & 167 & 31.7 & 33 & 22.8 & 200 & 29.8 \\
\hline & 4-6 months & 142 & 26.9 & 42 & 28.9 & 184 & 27.4 \\
\hline & $\geq 6$ months & 181 & 34.4 & 57 & 39.3 & 238 & 35.5 \\
\hline
\end{tabular}

*In those who received atleast one instalment of DBT.

†New patient's treatment duration was 6 months and eligible for three instalments of INR 1000 at 0,2 and 4 months after treatment initiation. Previously treated patient's treatment duration was 8 months and eligible for four instalments of INR 1000 at 0,2 , 4 and 6 months after treatment initiation. In case of extension of treatment, patient receives instalment of INR 1000 every 2 months. ‡Date of receipt of first instalment was ahead of treatment initiation date in four patients so not considered.

patients in whom treatment outcome reported, $12.8 \%$ suffered an unsuccessful TB treatment outcome.

\section{DBT coverage}

Overall, $771(42.2 \%)$ patients had received at least one instalment of DBT, $578(75.0 \%)$ of whom received all instalments. Significantly more patients from the public sector received the DBT compared with those from the private sector $(70.5 \%$ vs $11.1 \%, \mathrm{p}<0.001)$. In multivariable analysis, non-receipt of DBT was significantly associated with reactive HIV status (adjRR 2.7; 95\% CI 1.2 to 6.1) and treatment from the private sector (adjRR 16.3; 95\% CI 11.6 to 23.0) after adjusting for age, gender, place of residence and patient type (table 2). Among the 985 (54\%) patients who had a bank account, 214 (21.7\%) had not received DBT. The median (IQR) amount received was INR $3000(3000,3500)$ among DBT recipients. The median (IQR) time to receipt of first instalment after treatment initiation was $5.2(3.4,7.4)$ months. Only $7.3 \%$ $(49 / 671)$ patients got their first instalment of DBT within 2 months of treatment initiation in the public sector (table 3). Paediatric and geriatric patients were faced with significantly $(p=0.007)$ longer median (IQR) time to receipt of DBT compared with patients aged 15-59years old. Other factors associated with longer time to receipt of DBT were treatment from the private sector $(\mathrm{p}<0.001)$, residing outside the city limits $(\mathrm{p}<0.001)$ and non-reactive
HIV status $(\mathrm{p}<0.001)$ (table 4$)$. Non-recipients of DBT were significantly more likely to experience an unsuccessful TB treatment outcome compared with the recipients of DBT, after adjusting for age, gender, patient type, TB site and HIV status (adjRR 4.0; 95\% CI 2.6 to 6.1) (online supplementary file 4).

\section{Enablers for the implementation of DBT scheme \\ Perceived utility by providers}

The key informants viewed the DBT cash incentive as a valuable amount for the patients with $\mathrm{TB}$ to spend on nutritious food, especially among those belonging to lower income group and that it helped improve treatment adherence.

In private sector, some patients do not have money and go to consult private doctor, and then they are not taking medicines regularly. Now, because they are getting 500 rupees (INR) per month, those patients have started taking medicines regularly. Due to that defaulter rate [loss to follow-up] of TB came down and cure rate has gone up. (36-year-old, male provider)

Providers felt that compared with cash disbursement, direct transfer of the benefit to the beneficiary's bank account improved the chances that the benefit is being used for nutritional support as against cash, which 
Table 4 Factors associated with time to receipt first direct benefit transfer (DBT) instalment among patients with TB notified and initiated on first-line anti-TB treatment at City TB Centre Vadodara, India, between April and September $2018\left(n=767^{*}\right)$

\begin{tabular}{|c|c|c|c|c|}
\hline Factors & Category & $\begin{array}{l}\text { Median time to } \\
\text { receipt (months) }\end{array}$ & $\begin{array}{l}\text { IQR of time to receipt } \\
\text { (months) }\end{array}$ & $\mathbf{P}$ value \\
\hline Overall & & 5.2 & 3.4 to 7.4 & \\
\hline \multirow{2}{*}{ Age (in years) } & $15-59$ & 5.1 & 3.3 to 7.3 & \\
\hline & 60 and above & 5.7 & 3.8 to 7.5 & \\
\hline Gender & Female & 5.3 & 3.2 to 7.6 & \\
\hline \multirow[t]{3}{*}{ Residence } & Within city & 5.1 & 3.3 to 7.3 & $<0.001 \S$ \\
\hline & Outside city $\ddagger$ & 7.4 & 6.0 to 10.1 & \\
\hline & Not reported & 8.2 & 8.2 to 8.2 & \\
\hline HIV & Reactive & 3.5 & 2.7 to 7.3 & $<0.001$ \\
\hline Treatment sector & Private & 7.5 & 5.9 to 9.5 & \\
\hline \multirow[t]{2}{*}{ Patient type } & New & 5.2 & 3.3 to 7.5 & 0.452 \\
\hline & Previously treated & 5.4 & 3.6 to 7.4 & \\
\hline \multirow[t]{2}{*}{ Tuberculosis site } & Pulmonary & 5.2 & 3.4 to 7.5 & 0.497 \\
\hline & Extra pulmonary & 5.1 & 3.3 to 7.1 & \\
\hline
\end{tabular}

*Date of receipt of first instalment was ahead of treatment initiation date in four patients so not considered.

†Mann-Whitney $\mathrm{U}$ test used for two categories and Kruskal-Wallis $\mathrm{H}$ test for more than two categories.

$\ddagger$ Administrative area of City TB Centre, Vadodara.

$\S$ 'Not reported' category not included in calculation because only one record.

was more likely to be spent casually for miscellaneous purposes. They also felt that the bank transfers reduced the chances of corruption in handling cash.

....if wife has $\mathrm{TB}$, in many cases her husband may be having addiction like smoking, drinking alcohol; so he might be using this money for drinking alcohol. Or else, if husband is having TB, he would drink alcohol if we give him cash. (36-year-old, male provider)

Perceived adequacy of infrastructure and manpower

The providers felt that the updated nikshay software (December 2018) had helped them sail past the initial hiccups in implementation. Further, they felt that the smooth fund flow (timely and sufficient fund release), adequate work force and their established set-up with ample logistics were major enablers for the implementation of the scheme.

\section{Challenges in implementation of DBT scheme}

The emerging themes were broadly classified as systemrelated, provider-related and patient-related challenges against effective implementation of DBT scheme (table 5).

\section{System-related challenges}

During the initial months after launch of DBT scheme, the main challenge was nikshay software itself, which had many issues such as frequent changes to the software format, slow processing and data mismatch.

The bank account details of the patient that we were entering were not reflecting in nikshay software. Due to that, there was almost nil DBT payment in the initial months. (36-year-old, male provider)

There were issues in the PFMS portal also. Initially, there were some errors in linkage between nikshay and PFMS necessitating manual preparation of beneficiary list from PFMS. This added significant work burden on the providers and added to the delay in transfer of payment. Additionally, due to the absence of nikshay ID in PFMS generated list, it was difficult to track beneficiaries.

... we have to sit for preparation of manual list. The day when we sit can be any day when we are comparatively free from other work. Therefore, there is a chance of delay in payment. (29-year-old, male provider) 
Table 5 Challenges in implementation of direct benefit transfer (DBT) scheme for patients with tuberculosis and suggestions to solve them as perceived by key informants in City TB Centre, Vadodara, India, 2018

\begin{tabular}{|c|c|c|}
\hline Themes & Subthemes & Suggested solutions \\
\hline \multicolumn{3}{|l|}{ System level challenges } \\
\hline Issues with nikshay software & $\begin{array}{l}\text { - } \text { Frequent updates } \\
\text { - } \text { Slow performance of software } \\
\text { - } \text { Entered data not reflected in software } \\
\text { - } \text { DBT beneficiary list was based on notifying } \\
\text { facility earlier rather than current treatment } \\
\text { facility } \\
\text { - Difficulty in finding transferred patients }\end{array}$ & $\begin{array}{l}\text { Latest nikshay software update } \\
\text { Change to current treatment facility-based } \\
\text { DBT beneficiary list }\end{array}$ \\
\hline Issues with PFMS & $\begin{array}{l}\text { - Difficulty to trace beneficiary in public financial } \\
\text { management system (PFMS) generated sheet } \\
\text { due to the absence of nikshay ID } \\
\text { - } \text { Manual preparation of beneficiary list due to } \\
\text { error in nikshay-PFMS link } \\
\text { - Delay in approval }\end{array}$ & $\begin{array}{l}\text { PFMS data also to capture nikshay id } \\
\text { Direct nikshay-based payment } \\
\text { Direct district level DBT payment }\end{array}$ \\
\hline Issues with banks & $\begin{array}{l}\text { - Not inclined to open zero balance accounts } \\
\text { - } \text { Rural and cooperative banks are not on PFMS }\end{array}$ & $\begin{array}{l}\text { Bank to facilitate the process of opening } \\
\text { zero balance account }\end{array}$ \\
\hline \multicolumn{3}{|l|}{ Provider level challenges } \\
\hline Manpower involved in implementation &  & \\
\hline Private doctor related & $\begin{array}{l}- \text { Not obtaining complete patient details } \\
- \text { Reluctance to avail benefit for notification } \\
- \text { Busy/time constraints }\end{array}$ & $\begin{array}{l}\text { Encourage private providers to link patients } \\
\text { with public sector staff for document } \\
\text { procurement and processing }\end{array}$ \\
\hline \multicolumn{3}{|l|}{ Patient level challenges } \\
\hline Bank account & $\begin{array}{l}\text { - } \text { Lack of necessary documents } \\
\text { - Migrants and homeless patients } \\
\text { - } \text { Inability to maintain minimum balance } \\
\text { - } \quad \text { Dormant bank account } \\
\text { - } \quad \text { Unwillingness to pay account opening deposit }\end{array}$ & $\begin{array}{l}\text { Tie up with bank to open account on the } \\
\text { basis of treatment card in Vadodara city } \\
\text { Senior treatment supervisor (STS) } \\
\text { accompanies patient for opening account in } \\
\text { Vadodara city } \\
\text { Allow relatives bank account } \\
\text { Raise public awareness about zero balance } \\
\text { accounts facility from government }\end{array}$ \\
\hline Lack of awareness & $\begin{array}{l}\text { - About the DBT scheme benefits } \\
\text { - } \text { About documents required for enrolment }\end{array}$ & $\begin{array}{l}\text { Information education and communication } \\
\text { (IEC) about documents required and } \\
\text { benefits of scheme }\end{array}$ \\
\hline $\begin{array}{ll}\text { Unwilling to share details } & \text { (in private } \\
& \text { sector } \\
& \text { patients) }\end{array}$ & $\begin{array}{l}\text { - Doubts on confidentiality } \\
\text { - } \quad \text { Lack of trust } \\
\text { - } \quad \text { Uninterested in availing benefit }\end{array}$ & $\begin{array}{l}\text { Involve private doctors to obtain necessary } \\
\text { details of their patients } \\
\text { Provide DBT information and contact } \\
\text { person details card to private doctors for } \\
\text { distribution to their patients }\end{array}$ \\
\hline
\end{tabular}

\section{Provider-related challenges}

In private sector, the doctors link patients to government system for DBT. Key informants felt that effective and ongoing communication with patient is hampered since there is a lack of network of grassroot workers in private sector akin to the DOT providers of government sector. This led to incomplete or no details being collected from the patient to enable their enrolment into the scheme. Further, due to their busy work schedule and/or lack of motivation, some doctors were not inclined to facilitate the enrolment process for the patients.

Though they [private doctors] have to notify the case of TB to the government, to collect this type of information [bank details of patient] is not compulsory for them. (36-year-old, male provider)

\section{Patient level challenges}

The main challenge as observed by key informants for availing DBT benefit was non-availability of bank account with patients. Lack of valid identity proof for opening bank account was a major reason, especially among migrant and homeless patients.

Some patients, who are migrated here, do not have enough documents like ID proof, address proof. These patients do not have bank account so we are not able to pay DBT. (38-year-old, male provider)

Providers felt that patients' unwillingness to share their details including bank account and aadhaar (unique 12-digit identification number for Indians) was a major challenge in the private sector. Patients from higher 
socioeconomic strata were not interested in availing the benefit. Due to the stigma associated with TB, patients also feared breach of confidentiality.

...in private sector, some patients are financially well, so they do not require cash incentive and because of that, they are not giving details. (36-year-old, male provider)

...In private sector, the patients are high profile, so they have stigma related to TB and because of that, they are not giving their information to us. (49-year-old, female provider)

\section{Solutions to challenges in implementation}

A major respite to the software-related issues came with the latest update of the nikshay software in December 2018, following which no issues were faced in entry of patient details. Base for generation of DBT beneficiary list has also been changed from notification centre to current treatment facility. City TB Centre, Vadodara has also prepared cards with the contact details of public-private coordinator, that the private sector doctors may handover to the patient thus directing them to the programme staff for enrolment under DBT scheme.

We have printed our visiting cards, which we give to the private doctors. Doctors give it to their patients. Therefore, the patient sends their details directly to our office or via WhatsApp. Due to this method, the patient can trust us when we call them. (36-year-old, male provider)

Raising awareness about zero balance bank account among public and bank staff was a suggested solution. Providers felt that patients with TB must be helped to open bank accounts by the healthcare staff with the treatment card or a letter from the medical officer as a supporting document.

For migrants and those who do not have documents, we made liaison with post office and **** [private] bank. They open the account of patients of TB based on our recommendation letter. (55-year-old, male provider)

\section{Patient perspectives and experiences about DBT}

Majority of the patients were aware that they were eligible to receive a benefit of INR 500 per month and the process involved therein.

...I submitted it [her documents] via WhatsApp [to NTP staff]. I did not face any difficulty in availing this benefit. (26-year-old, female patient from private sector who received DBT)

Majority of the patients who received DBT used it for nutrition-to purchase milk, fruits, food.

I have been told by doctor to consume milk, fruits etc. during illness. For that, there is a need of money, so this money became helpful to me. I was taking milk daily at night. (36-year-old, male patient from public sector who received DBT)

Two out of 11 patients were not aware that they received cash incentive in their bank account until the PI requested them to verify their bank passbooks.

I do not know. Because I have not checked my bank account statement. [Patient verified his bank passbook and confirmed the credit of DBT on request by PI]. (44-year-old, male patient from private sector who received DBT)

Some patients in the private sector perceived it as a support to meet their expense of medicines, while one patient felt that this is an inadequate amount.

...500 rupees [INR] per month is not enough; it should be increased to $800-1000$ rupees [INR] per month. (68-year-old, male patient from public sector who did not received DBT)

\section{DISCUSSION}

The study presents the findings from the first 6-month cohort of patients with $\mathrm{TB}$, receiving cash incentive under the recently launched DBT scheme from Western India, providing timely and realistic inputs to the National TB Control Programme.

\section{DBT scheme coverage}

Two-fifths of the 1826 enrolled patients had received DBT. Considering the teething problems in the initial months for any scheme after its launch, the coverage is good in the first 6-month cohort. Compared with our study, Wingfield et al (Peru, 90\%) ${ }^{12}$ and Torrens et al (Brazil, 80\%) ${ }^{20}$ observed higher coverage for conditional cash transfer. Possible reasons may be that our study included patients under programmatic settings without any condition for cash transfer, whereas Wingfield et al's conclusions were based on only 122 participants who volunteered for participation and Torrens et al studied patients with TB who were also the beneficiaries of another conditional cash transfer programme in Brazil.

\section{Time to receipt of DBT}

It is widely known that households with $\mathrm{TB}$ in India experience a high catastrophic cost of $\mathrm{TB}$ care during treatment. ${ }^{121}$ Non-medical expenses such as those due to additional food and transport expenses were twice as much as the medical costs ${ }^{12}$ and mostly occur in the intensive phase of TB treatment. ${ }^{12}$ Timely receipt of the instalment is thus essential so that patient can actually spend the amount on nutrition and other disease-related expenses. Among DBT recipients in our study, less than $10 \%$ received their first instalment of DBT within 2 months of treatment initiation and the median time to receipt of first instalment was 5 months. Torrens $e t a l^{20}$ also reported one-fifth of the patients receiving cash transfers only after the end of treatment. One reason for the observed delay 
could be that we have studied an early cohort of patients while the scheme is still in its nascent phase.

Many studies documented the positive association between receipts of cash transfer and improved treatment outcome. ${ }^{2022-27}$ Positive association between DBT receipt and successful treatment outcomes was also found in our study. However, there are certain limitations that prevent us from a definite conclusion in this regard. First, DBT receipt was assessed during treatment and not at baseline. Second, as the time to DBT receipt was long, those who were retained in care for long periods are more likely to be grouped under 'receiving DBT', while those who suffer unsuccessful outcomes (especially during the initial months of treatment) are more likely to be grouped under those who 'did not receive DBT'. Third, comparison with a historical cohort before implementation of the DBT scheme was precluded by the fact that the scheme implementation was also accompanied by a change in the TB treatment regimen from intermittent to daily regimen.

\section{Enablers and challenges to DBT implementation}

Cash transfer schemes have potential to follow an 'inverse care law' in which most impoverished countries with high prevalence of TB are least able to afford the cash transfer scheme. ${ }^{28}{ }^{29}$ Contrary to this, despite being in its early days, the providers felt that the DBT scheme in their city enjoyed a smooth fund flow, had adequate work force and well-established infrastructure with ample logistics. Nevertheless, there were also challenges that were related to the system, provider or patient.

Patients from the private sector were significantly less likely to have received the DBT. About $40 \%$ of patients with $\mathrm{TB}$ are treated in the private health sector in India. ${ }^{30}{ }^{31} \mathrm{As}$ the notification of TB cases being mandatory for private practitioners, there is no major issue related to listing of private sector patient on government portal (nikshay). The public health system enjoys the network of frontline level workers for smooth implementation of DBT among public patients. In the absence of such a network in the private sector, the private doctor is expected to be assuming a key mediator role for the DBT process. However, facilitating the process of DBT is not mandatory for private doctor. Due to various reasons like busy work schedule, lack of motivation and lack of awareness, some doctors are not inclined to facilitate this process. Another challenge in the private sector is the patients' unwillingness to share their details due to various reasons like lack of trust in government system for confidentiality of their data, stigma associated with TB and no perceived need for the cash support specifically among patients from higher socioeconomic strata. Despite existence of active public-private mix efforts, motivating the diverse, fragmented and under-regulated private sector ${ }^{32}$ is a challenge yet to be surmounted. ${ }^{31}$

Another major barrier to availing DBT was that only $53.9 \%$ of the patients held bank accounts, which was a mandatory requirement to receive the benefit. Despite a high literacy rate in Vadodara city, bank account holding in our study was less than the estimated average of $80 \%$ in India. ${ }^{33}$ Vadodara city is home to a lot of migrant people from other states predominantly employed in the unorganised sector who are faced with the challenge of not having documents for opening the bank account, thereby being deprived of access to DBT. Some patients with bank accounts, especially those in the private sector, refused to provide the details due to confidentiality and trust-related issues. Even among those who held bank accounts, some patients had not received the benefit because either the bank was not in the list of PFMS or they had shifted out of public sector, to receive treatment elsewhere.

Challenges related to nikshay and PFMS as perceived by key informants were mostly solved with the latest update of nikshay in December 2018.

We feel that the current policy to give cash transfer spread throughout the treatment rather than giving lump sum at the beginning of treatment is appropriate to improve treatment adherence. DBT in patient's bank account is also important to ensure timely payment of cash incentive directly to the patient. The Government of India started DBT programme since 2013 for several centrally sponsored schemes; to bring transparency, reduce delay, prevent duplication and terminate pilferage in transfer of subsidies to the intended beneficiaries. Inspired from good results of DBT programme, NTP also adopted DBT for cash transfer to people with TB. Although the DBT promises effective cash transfer to the beneficiary, the system cannot work if the beneficiary does not have a bank account; and unfortunately, banking penetration among the target beneficiaries is limited, especially in urban slums and rural areas. On the contrary, if NTP moves beyond the DBT and eliminate requirement of bank account for cash transfer, there are chances of fraud and many intended beneficiaries might not get the cash benefit. To deal the issue of non-availability of bank accounts with beneficiaries, the government of India already introduced 'Pradhan Mantri Jan Dhan Yojana' in a big way and the programme is quite successful. Under this scheme, the government provides basic bank accounts (especially to poor people) with the facility of 'no minimum balance' or say 'zero balance' in account.

\section{Limitations of the study}

The study was conducted on the first cohort of beneficiaries of DBT scheme, and considering some challenges for implementation in initial months, coverage of DBT may have been lower than what would be achieved after a period of stabilisation.

Due to longer follow-up time required for ascertaining receipt of at least one instalment of DBT in case of patients with MDR-TB (which was falling beyond the study period), we could not include them in the study.

Although the socioeconomic status is one of the important factors affecting the DBT receipt status, we 
would not able to include it in the study because of its non-availability in quantitative secondary data.

\section{CONCLUSION}

To conclude, DBT coverage was found to be reasonable for the first 6-month cohort of beneficiaries. However, the coverage was low in the private sector. Time to the receipt of first instalment of DBT after treatment initiation was much longer, for which the main reason was nikshay software-related issues in initial months. The main challenge for effective implementation of DBT was non-availability of bank account with patients, which is a mandatory requirement to avail of the benefit. In the private sector, key challenges were lack of support from private providers and patients' unwillingness to share their details.

\section{Recommendations}

Based on study findings, we would like to recommend some measures for effective implementation of DBT scheme. Facilitation of process of opening bank accounts for patients with TB should be focused. Awareness about the zero balance account scheme must be improved among the public, bank staff and programme staff. To tackle the issue of lack of documents to open bank account, patients with TB may be allowed to open a bank account based on a letter certifying their disease status from district/city TB officer. However, this may require the physician to reveal the disease status of the patient, thereby compromising physician-patient confidentiality and raise ethical issues. Mobile notifications to beneficiaries about credit of their DBT cash incentive should be done by NTP to enable timely utilisation of the benefit. Avenues for effective involvement of private sector in DBT scheme need to be explored further. There is a need to reconsider the mandatory requirement of bank account for availing cash benefit. Some alternate options for cash transfer can be considered for those who could not open the bank account after all efforts.

\section{Author affiliations}

${ }^{1}$ Community Medicine Department, GMERS Medical College, Vadodara, Gujarat, India

${ }^{2}$ Scientist-D, ICMR- National Institute of Epidemiology, Chennai, Tamilnadu, India

${ }^{3}$ Department of Preventive and Social Medicine, Jawaharlal Institute of

Postgraduate Medical Education and Research (JIPMER), Puducherry, India

${ }^{4}$ Consultant-II, Division- Online Courses, ICMR- National Institute of Epidemiology, Chennai, Tamilnadu, India

${ }^{5}$ Community Medicine Department, GMERS Medical College, Gandhinagar, Gujarat, India

${ }^{6}$ Public Health Department, Commissionerate of Health, Health and Family Welfare Department, Government of Gujarat, Gandhinagar, Gujarat, India

${ }^{7}$ City TB Centre, Vadodara Municipal Corporation, Vadodara, Gujarat, India

${ }^{8}$ Centre for Operational Research, International Union Against Tuberculosis and Lung Disease (The Union), Paris, France

${ }^{9}$ Operational Research, The Union South-East Asia Office, New Delhi, India

${ }^{10}$ Community Medicine Department, MP Shah Government Medical College, Jamnagar, Gujarat, India

${ }^{11}$ Department of Community Medicine, Yenepoya Medical College, Yenepoya (Deemed to be University), Mangaluru, Karnataka, India

\section{Twitter Hemant Deepak Shewade @HShewade}

Acknowledgements This research was conducted through the Structured Operational Research and Training Initiative (SORT IT), a global partnership led by the Special Programme for Research and Training in Tropical Diseases at the World Health Organization (WHO/TDR). The model is based on a course developed jointly by the International Union Against Tuberculosis and Lung Disease (The Union) and Medécinssans Frontières (MSF/Doctors Without Borders). The specific SORT IT programme, which resulted in this publication, was jointly developed and implemented by The Union South-East Asia Office, New Delhi, India; the Centre for Operational Research, The Union, Paris, France; Department of Community Medicine Department, GMERS Medical College, Vadodara, India; Department of Preventive and Social Medicine, Jawaharlal Institute of Postgraduate Medical Education and Research, Puducherry, India; National Institute of Epidemiology, Chennai, India; Department of Community Medicine Department, GMERS Medical College, Gandhinagar, India; State TB Cell, Health and Family Welfare Department, Government of Gujarat, Gandhinagar, India; City TB Centre, Vadodara, India; Department of Community Medicine, Yenepoya Medical College, Yenepoya (Deemed to be University), Mangaluru, India; and National Institute for Research in Tuberculosis, Chennai, India. We acknowledge Dr Manoj Makwana, Medical Officer and Mrs Leena D. Changrani, programme coordinator from City TB Centre, Vadodara for their support in data collection process.

Contributors BHP, HDS and KGM conceptualised the study subject. BHP, KJ and PC worked together to design study protocol. KGM and BM contributed in study design by critical revision. BHP, KJ, PC and MV jointly developed data capture tool and BHP did data collection. BHP, KJ, PC, BM, PDC, KGM and MV contributed to data analysis and interpretation. BHP, KJ and PC in collaboration prepared first draft of manuscript. AMVK, PVD, CCZ, DMS, HDS, BM, PDC, KGM, MV, BHP, KJ and PC read, critically reviewed and approved the final manuscript.

Funding The training programme within which this paper was developed and the open access publication costs were funded by the Department for International Development (DFID), UK and La Fondation Veuve Emile Metz-Tesch (Luxembourg).

Disclaimer The funders had no role in study design, data collection and analysis, decision to publish or preparation of the manuscript.

Competing interests None declared.

Patient consent for publication Not required.

Ethics approval Ethics approval was obtained from the Institutional Human Ethics Committee of GMERS Medical College, Vadodara, Gujarat, India (IHEC number: 204/2018) and the Ethics Advisory Group of the International Union Against Tuberculosis and Lung Disease, Paris, France (EAG number: 94/18). Informed consent was obtained from all participants interviewed. A waiver for informed consent was obtained from the ethics committees for the quantitative data.

Provenance and peer review Not commissioned; externally peer reviewed.

Data availability statement All data relevant to the study are included in the article or uploaded as supplementary information. Data do not include patient identifiable data.

Open access This is an open access article distributed in accordance with the Creative Commons Attribution Non Commercial (CC BY-NC 4.0) license, which permits others to distribute, remix, adapt, build upon this work non-commercially, and license their derivative works on different terms, provided the original work is properly cited, appropriate credit is given, any changes made indicated, and the use is non-commercial. See: http://creativecommons.org/licenses/by-nc/4.0/.

ORCID iD

Bharatkumar Hargovandas Patel http://orcid.org/0000-0003-1847-0345

\section{REFERENCES}

1 Tanimura T, Jaramillo E, Weil D, et al. Financial burden for tuberculosis patients in low- and middle-income countries: a systematic review. Eur Respir J 2014;43:1763-75.

2 Liu Q, Smith $\mathrm{H}$, Wang Y, et al. Tuberculosis patient expenditure on drugs and tests in subsidised, public services in China: a descriptive study. Trop Med Int Health 2010;15:26-32.

3 Zhang T, Tang S, Jun G, et al. Persistent problems of access to appropriate, affordable TB services in rural China: experiences of different socio-economic groups. BMC Public Health 2007;7:1-12.

4 Meng Q, Li R, Cheng G, et al. Provision and financial burden of TB services in a financially decentralized system: a case study 
from Shandong, China. Int J Health Plann Manage 2004;19(Suppl 1):S45-62.

5 Getahun B, Wubie M, Dejenu G, et al. Tuberculosis care strategies and their economic consequences for patients: the missing link to end tuberculosis. Infect Dis Poverty 2016;5:1-10.

6 Fuady A, Houweling TAJ, Mansyur M, et al. Catastrophic total costs in tuberculosis-affected households and their determinants since Indonesia's implementation of universal health coverage. Infect Dis Poverty 2018;7:1-14.

7 Wingfield T, Tovar MA, Huff D, et al. Beyond pills and tests: addressing the social determinants of tuberculosis. Clin Med 2016;16:s79-91.

8 United Nations General Assembly. Transforming our world: the 2030 agenda for sustainable development [Internet], 2015. Available: https://sustainabledevelopment.un.org/content/documents/ 21252030 Agenda for Sustainable Development web.pdf [Accessed 12 Jul 2019].

9 World Health Organization. The end TB srategy [Internet], 2015. Available: http://www.who.int/tb/End_TB_brochure.pdf

10 Rudgard WE, Evans CA, Sweeney S, et al. Comparison of two cash transfer strategies to prevent catastrophic costs for poor tuberculosis-affected households in low- and middleincome countries: an economic modelling study. PLoS Med 2017;14:e1002418-28.

11 Gopalan SS, Mutasa R, Friedman J, et al. Health sector demandside financial incentives in low- and middle-income countries: a systematic review on demand- and Supply-side effects. Soc Sci Med 2014;100:72-83.

12 Wingfield T, Tovar MA, Huff D, et al. The economic effects of supporting tuberculosis-affected households in Peru. Eur Respir $J$ 2016;48:1396-410.

13 Ukwaja KN, Alobu I, Mustapha G, et al. 'Sustaining the DOTS': stakeholders' experience of a social protection intervention for TB in Nigeria. Int Health 2017;9:112-7.

14 Central TB Division, Governemnt of India. National strategic plan for tuberculosis: 2017-25 elimination by 2025, 2017. Available: https:// tbcindia.gov.in/WriteReadData/National Strategic Plan 2017-25.pdf

15 Creswell J, Plano Clark VL, Gutmann M, et al. Advance mixed methods research designs. In: Handbook of mixed methods in social and behavioral research, 2003: 209-40.

16 Office of the Commissioner \& Registrar General of the Indian 2011 Census. Population census 2011. Data on Vadodara city. Available: https://www.census2011.co.in/census/city/338-vadodara.html [Accessed 12 Jul 2019].

17 Health and Family Welfare Department Government of India. India TB report 2018 : annual status report, 2018. Available: https://tbcindia. gov.in/showfile.php?lid=3314 [Accessed 12 Jul 2019].

18 Attride-Stirling J. Thematic networks: an analytic tool for qualitative research. Qual Res 2001;1:385-405.
19 Tong A, Sainsbury P, Craig J. Consolidated criteria for reporting qualitative research (COREQ): a 32-item checklist for interviews and focus groups. Int J Qual Health Care 2007;19:349-57.

20 Torrens AW, Rasella D, Boccia D, et al. Effectiveness of a conditional cash transfer programme on TB cure rate: a retrospective cohort study in Brazil. Trans $R$ Soc Trop Med Hyg 2016;110:199-206.

21 Prasanna T, Jeyashree K, Chinnakali P, et al. Catastrophic costs of tuberculosis care: a mixed methods study from Puducherry, India. Glob Health Action 2018;11:1477493-9.

22 Sripad A, Castedo J, Danford N, et al. Effects of Ecuador's national monetary incentive program on adherence to treatment for drugresistant tuberculosis. Int J Tuberc Lung Dis 2014;18:44-8.

23 Ciobanu A, Domente L, Soltan V, et al. Do incentives improve tuberculosis treatment outcomes in the Republic of Moldova? Public Health Action 2014;4:59-63

24 Rocha C, Montoya R, Zevallos K, et al. The innovative socioeconomic interventions against tuberculosis (ISIAT) project: an operational assessment. Int J Tuberc Lung Dis 2011;15(Suppl 2):50-7.

25 Ukwaja KN, Alobu I, Gidado M, et al. Economic support intervention improves tuberculosis treatment outcomes in rural Nigeria. Int $J$ Tuberc Lung Dis 2017;21:564-70.

26 Klein K, Bernachea MP, Iribarren S, et al. Correction: evaluation of a social protection policy on tuberculosis treatment outcomes: a prospective cohort study. PLoS Med 2019;16:e1002826.

27 J Carter D, Daniel R, Torrens AW, et al. The impact of a cash transfer programme on tuberculosis treatment success rate: a quasiexperimental study in Brazil. BMJ Glob Health 2019;4:e001029.

28 Chiwele DK. Assessing administrative capacity and costs of cash transfer schemes in Zambia implications for Rollout country study. International Policy Centre for Inclusive Growth, United Nations Development Program, 2010: 20. 1-47.

29 Tudor Hart J. The inverse care law. The Lancet 1971;297:405-12.

30 Satyanarayana S, Nair SA, Chadha SS, et al. From where are tuberculosis patients accessing treatment in India? results from a cross-sectional community based survey of 30 districts. PLoS One 2011;6:e24160-8.

31 Anand T, Babu R, Jacob AG, et al. Enhancing the role of private practitioners in tuberculosis prevention and care activities in India. Lung India 2017;34:538-44.

32 Wells WA, Uplekar M, Pai M. Achieving systemic and scalable private sector engagement in tuberculosis care and prevention in Asia. PLoS Med 2015;12:e1001842.

33 International bank for reconstruction and Development/The world bank. The global Findex database 2017: measuring financial inclusion and the Fintech revolution, 2018. Available: https:// openknowledge.worldbank.org/bitstream/handle/10986/29510/ 211259ov.pdf 